\title{
The rheological behaviour of porous magmas: Bubbles vs. Vesicles
}

\author{
Stefania Sicola ${ }^{1}$, Alessandro Vona ${ }^{1}$, Claudia \\ ROMANO $^{1 *}$, AMY G. RYAN ${ }^{2}$, JAMES K. RUSSELL ${ }^{2}$
}

${ }^{1}$ Dipartimento di Scienze, Università degli Studi Roma Tre, Italy (*correspondence: claudia.romano@uniroma3.it)

${ }^{2}$ Earth, Ocean and Atmospheric Sciences, University of British Columbia, Vancouver, Canada

The presence of pores strongly controls the rheological behavior of magma and thus influences all volcanic processes (pre- syn- and post-eruptive). Nevertheless, the effects of porosity on magma rheology are still unresolved and subject to debate.

Here we present a new set of experiments designed to investigate the rheology of pore-bearing melts at high temperature $\left(750-800^{\circ} \mathrm{C}\right)$, low strain rates $\left(10^{-6}-10^{-7} \mathrm{~s}^{-1}\right)$ and variable porosity (10-70\% vol.). Experiments were performed at $1 \mathrm{~atm}$ using a Thermomechanical Analyzer (TMA) on 5 x 5 $\mathrm{mm}$ cores of natural rhyolitic obsidian from Krafla, Iceland (vesicle and crystal-free) initially containing $0.11 \mathrm{wt} \%$ dissolved $\mathrm{H}_{2} \mathrm{O}$.

Our experiments comprise two steps. First, cores are heated above the glass transition temperature interval $(900$ $\left.1050^{\circ} \mathrm{C}\right)$ and held for set times $(10-24 \mathrm{~h})$ to create bubblebearing cores. Second, the cores are deformed at lower temperatures $\left(750\right.$ or $\left.800^{\circ} \mathrm{C}\right)$ under a constant load $(150 \mathrm{~g})$ for 5-20 hours. We have employed two different strategies for the second step: i) samples were deformed in situ directly after foaming (single-stage, SS); or ii) samples were deformed at temperature after 15 days repose at room $\mathrm{T}$ (double-stage, DS). Our experiments provide data on the effects of porosity on the viscosity of natural rhyolitic deposits (e.g., ignimbrite, lava). Discordant results from single-stage vs. double stage experiments suggest that the rheology of porous volcanic materials depends on whether pores are vapor-filled (e.g., lavas) or are empty and connected by cracks (e.g., pyroclastic deposits). 